East African Medical Journal Vol. 83 No. 10 October 2006

PERFORATED MECKEL'S DIVERTICULITIS PRESENTING AS A MESENTERIC ABSCESS: CASE REPORT

R. Wasike, MBChB, MMed (Surg) and H. Saidi, BSc, MBChB, MMed (Surg), FCS, Aga Khan University Hospital, P.O. Box 30270-00100, Nairobi, Kenya

Request for reprints to: Dr. R. Wasike, Aga Khan University Hospital, P.O. Box 30270-00100, Nairobi, Kenya

\title{
PERFORATED MECKEL'S DIVERTICULITIS PRESENTING AS A MESENTERIC ABSCESS: CASE REPORT
}

\author{
R. WASIKE and H. SAIDI
}

\begin{abstract}
SUMMARY
Only $2 \%$ of patients with Meckel's diverticulae (MD) will manifest clinical problems. Diverticulitis occurs in approximately $10-20 \%$ of patients with symptomatic MD and more often in the elderly population. We report a case of Meckels diverticulitis presenting with perforation and mesenteric abscess in a young African man. The authors present information on diagnostic pitfalls and advise a lower threshold for consideration of MD as a differential diagnosis of acute right iliac fossa pain especially when the CT scan denotes a normal appendix in a male patient.
\end{abstract}

\section{INTRODUCTION}

Meckel's diverticulum (MD) represents a remnant of the omphalomesenteric duct and is present in 1$4 \%$ of the population $(1,2)$. A preoperative diagnosis of symptomatic diverticulum is seldom established due to non-specific symptomatology. Only $10 \%$ are diagnosed at CT scan imaging (3). The morbidity and mortality associated with removal of symptomatic MD can peak to $20 \%$ and $2-5 \%$ respectively (4). The dominant complications are hemorrhage and intestinal obstruction, reportedly common in children and older patients respectively. The removal of asymptomatic MD is reported to be associated with complications that may be as high as $8 \%$ (5). Cases of MD and associated complications have rarely been reported in our region (6).

\section{CASE REPORT}

A 26-year-old male banker presented with a 10-day history of abdominal pain, nausea and fever. The pain was initially paraumbilical and poorly localized but colicky in nature. It later localized in the right iliac fossa and associated with vomiting. He had preceding diarrhoea and received treatment for amoebiasis as an outpatient. He had no significant previous medical or surgical history.

On admission, his general condition was fair but had a body temperature of $38^{\circ} \mathrm{C}$. Abdominal examination revealed a tender right iliac fossa mass. The rest of the abdominal examination as well as the examination of the other systems were unremarkable. He had a leucocyte count of $20.7 \times 10^{9} / 1$ (neutrophilia $81 \%$ ) but normal electrolytes, renal and liver function tests. Serum amylase, lipase and plain abdominal radiographs were reported as normal. A high resolution spiral CT scan of the abdomen showed an abscess in the small bowel mesentery measuring $5.5 \mathrm{~cm} \times 6.0 \mathrm{~cm}$ (Figures 1 and 2). The appendix and caecum were normal. At that time the diagnosis of mesenteric abscess was entertained. At laparotomy, an inter-loop abscess was drained. The ileal loops had walled off an inflamed and perforated Meckel's diverticulum. The contiguous areas of the ileum were gangrenous. En bloc resection of the gangrenous ileum together with the perforated Meckel's diverticulum was performed (Figure 3). The bowel ends were anastomosed primarily.

Histopathological examination showed a gangrenous perforated Meckel's diverticulum. The patient's post-operative course was uneventful. 
Figure 1

Transverse CT scan showing an abscess (arrow) in the right lower quadrant of the abdomen. The abscess is delineated between loops of contrast-filled intestines (arrow heads).

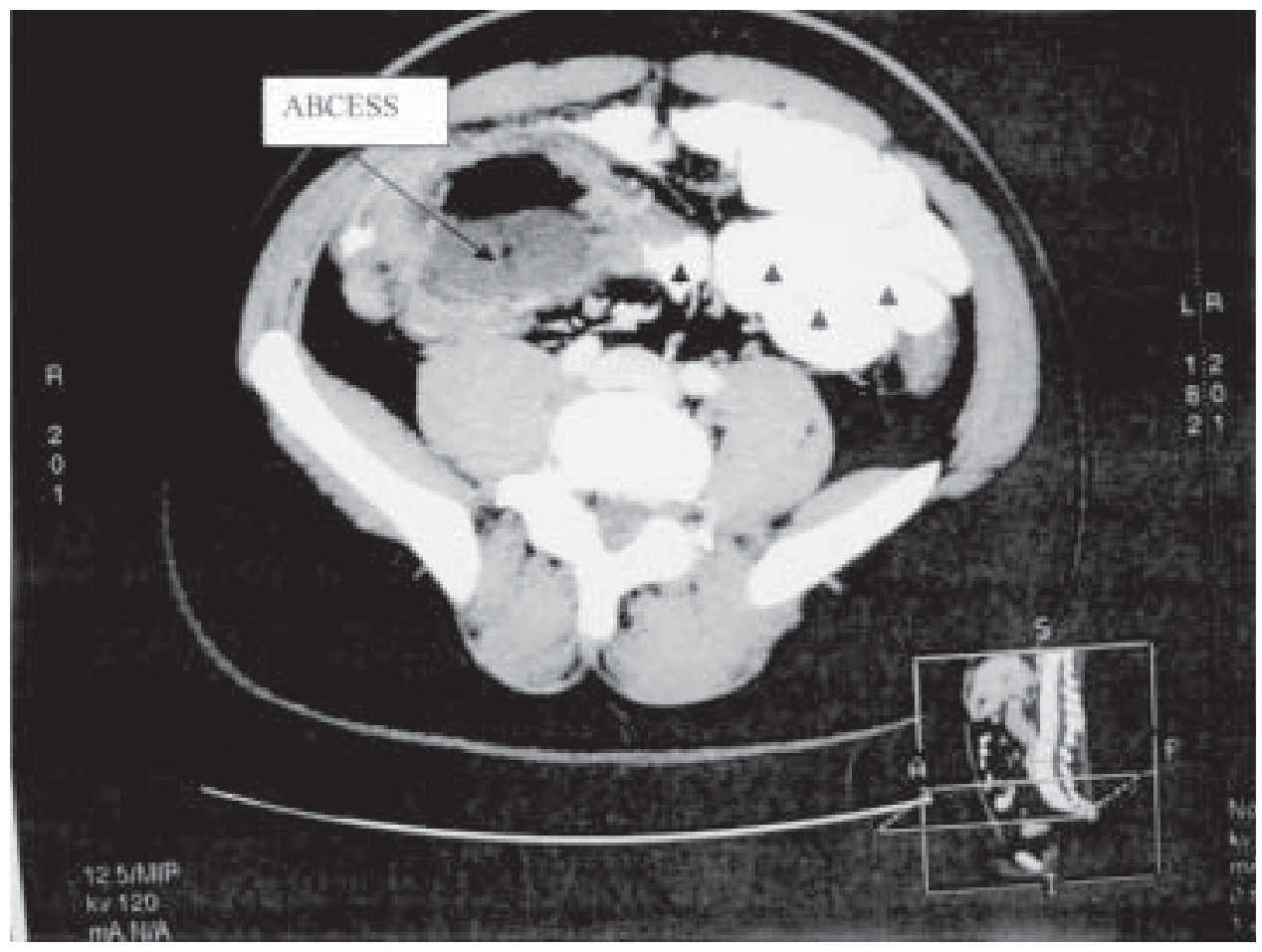

Figure 2

Formatted CT scan showing the position of the interloop abscess (A). The picture in this scan is typical of a mesenteric abscess. (B-intestinal loop)

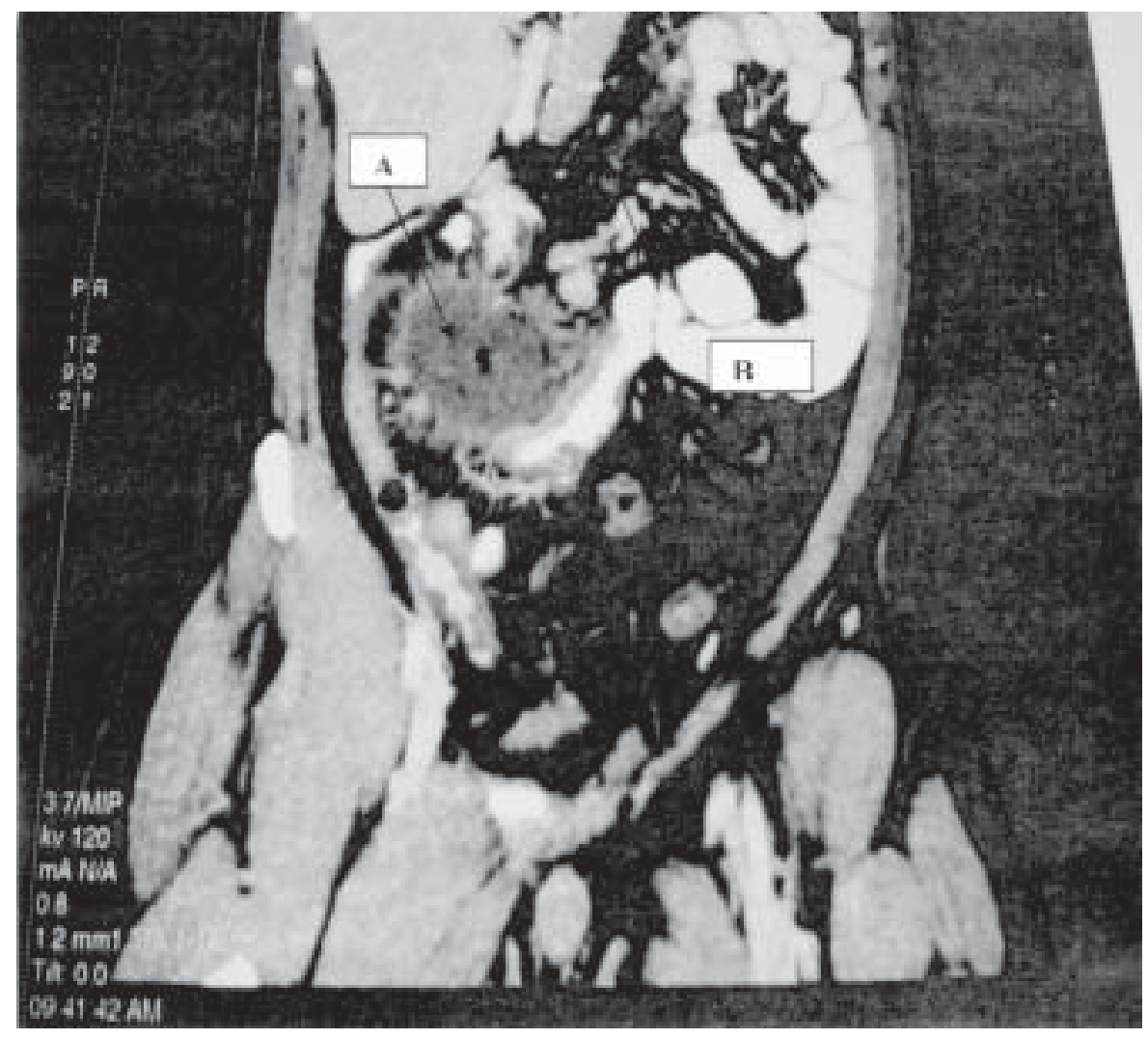




\section{Figure 3}

Resection specimen. The Meckel diverticulum with a demonstrably wide base (arrow). The adjacent areas of the ileum were non viable (arrow heads)

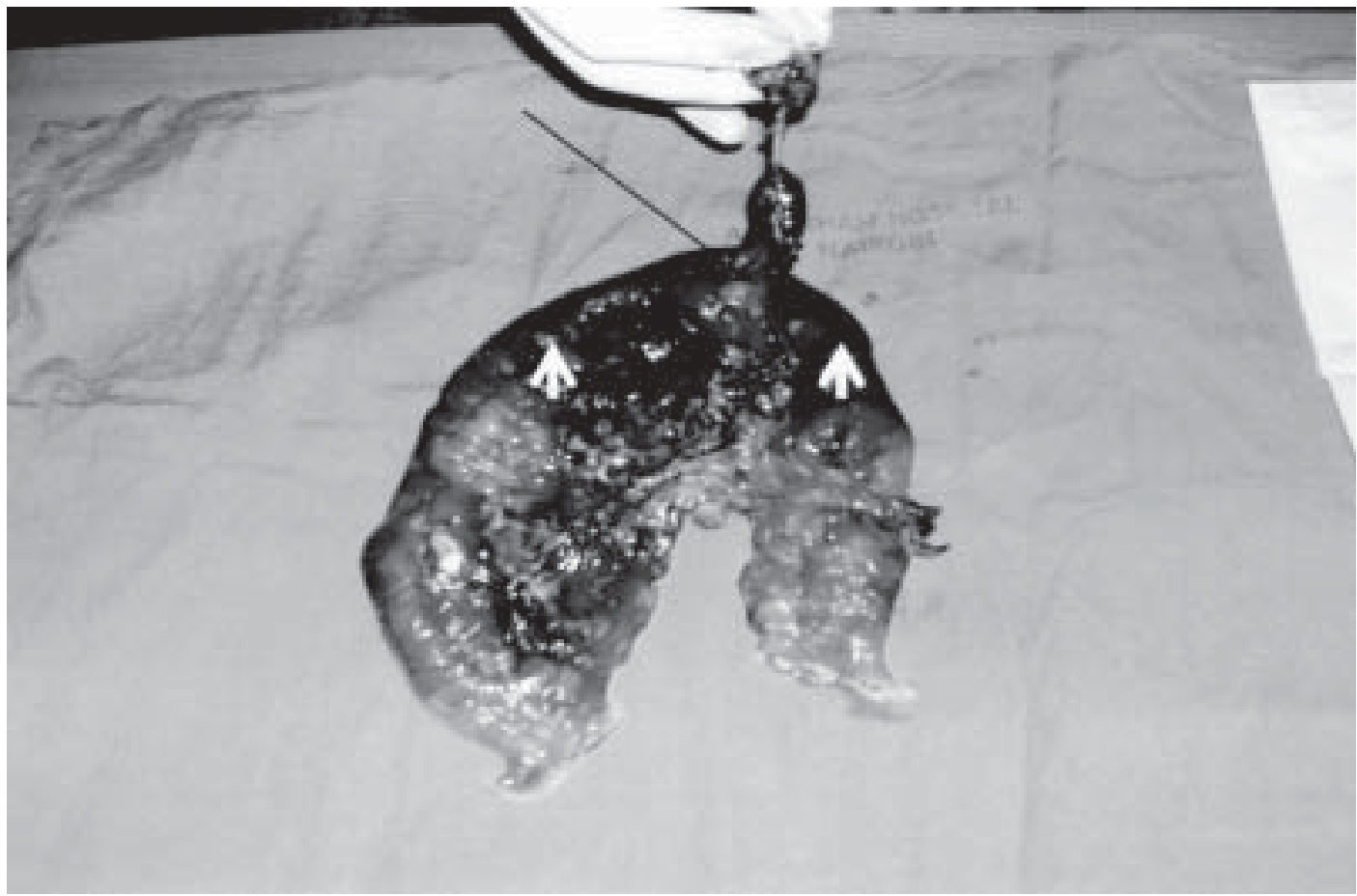

\section{DISCUSION}

Acute inflammation is an uncommon complication of Meckel's diverticulum. Unlike the vermiform appendix, which is predisposed to frequent inflammation, Meckel's diverticulum is a selfemptying structure possessing a wide mouth and little lymphoid tissue (I). Diverticulitis develops when the mouth is narrowed by enteroliths, parasites, neoplasms or fibrosis due to peptic ulceration (7). This is only the second report of complicated Meckel's diverticulitis in East Africa (6). Reports elsewhere also indicate the rarity of the condition. At a University in Gottingen for example, only 34 patients underwent resection for complicated MD over a 27-year period (8) with less than $15 \%$ due to diverticular perforation. At the Mayo clinic, symptomatic MD formed $16 \%$ of 1,479 diverticulae resected over a period of 52 years (2). The complication described in the 26-year old male in this report was disguised as a mesenteric abscess. A common clinical entity associated with the presentation outlined in this case is complicated appendicitis. Clinical differentiation between diverticulitis and appendicitis is difficult. This may be easier in children than in adults. A higher proportion of diverticulae in children contain gastric and pancreatic heterotopic tissue (3). Associated bleeding due to ulceration of gastric mucosa may help to distinguish the complication of diverticulitis from that of appendicitis. Radiologically, a technitium 99m pertechnetate (Meckel) scan is a useful diagnostic tool in children (sensitivity $85 \%$, specificity $95 \%$ ) as it depends on the uptake of the isotope in the heterotopic gastric tissue (7). Adult patients are rarely reported to present with haemorrhage (9). Non-specific presentations of intestinal obstruction, diverticulitis, volvulus and enterolith formation, make it difficult to establish a correct diagnosis before surgery in adults.

The preoperative CT performed scan in our patient confirmed a normal vermiform appendix. It also revealed a mesenteric abscess related to the distal ileum. Establishment of a preoperative CT diagnosis of Meckel's diverticulitis is unusual as it is difficult to distinguish the diverticulum from intestinal loops unless attachment to the umbilicus can be demonstrated (3). When situated closer to the midline and away from the right iliac fossa however, the pick-up rate increases. In the account 
by Bennet et al, seven out of eleven lesions were preoperatively diagnosed on CT scan especially for diverticuli close to the midline(10). Suggestive findings include a tubular inflammatory mass originating from a loop of bowel around the distal ileum. The size, wall thickness and contents of the lesion are variable and it is situated away from the caecum and appendix. Differential diagnoses to be considered would include complicated Crohn's disease, mesenteric cyst, urachal remnants, intestinal ischaemia or small bowel tumour (11) When invaginated, the diverticulum appears as an intraluminal prolonged mass with a central area of fat density and a peripheral collar (7). Urachal cyst appears as a fluid filled lesion related to the dome of the bladder and attached to the umbilicus. Crohn's disease is diagnosed on CT by the absence of a diverticulum and the presence of mesenteric fibrofatty proliferation, fistula formation and colonic involvement (10).

The demonstrated abscess cavity in this case indicated the need for surgery- the usual approach by which the diagnosis of adult complicated diverticulitis is made. We contend however that the combination of symptoms, physical signs and visualization of normal appendix on the $\mathrm{CT}$ image, (in the atypical cases where $\mathrm{CT}$ is indicated) should raise the suspicion for complicated Meckel diverticulitis, especially in the male patient.

Our patient had an uneventful postoperative recovery. The morbidity and mortality related to diverticulectomy for symptomatic MD approach $20 \%$ and $5 \%$ respectively (4). Other estimates indicate a likelihood of complication in Meckel's diverticulum of only $4 \%$ in patients up to 20 years of age with further risk reduction with increasing age (11). Yet others have reported a complication rate following surgical removal of an incidental MD of up to $8 \%(5,12,13)$. Prophylactic removal would then seem unjustified unless the MD is associated with factors that increase the risk of complication including male gender, age younger than 40 years, presence of suspected heterotopic tissue (10)

In conclusion, symptomatic MD requiring operation is more common in men (ratio of about 3:1) (2). The diagnosis of complicated Meckel's diverticulum should be considered in male adults presenting with features of right iliac fossa inflammatory mass away from a normal caecum and appendix on CT.

\section{ACKNOWLEDGEMENT}

We thank Prof. Mushtaq Ahmed for reading the manuscript. This paper was presented at the annual conference of the surgical society of Kenya, Eldoret, 2005.

\section{REFERENCES}

1. Keljo D.J. and Squires R.H. Jr. Anatomy and anomalies of the small and large intestines. In: Feldman M., Scharschmidt B.F., Sleisenger M.H., Klein S. (eds). Sleisenger \& Fordtran's gastrointestinal and liver disease, $6^{\text {th }}$ edition. 1998, Philadelphia: W. B. Saunders Company, pp. 1426-1428.

2. Park J.J., Wolff B.G., Tollefson M.K., Walsh E.E. and Larson D.R. Meckel diverticulum: The Mayo Clinic experience with 1476 patients (1950-2002). Ann. Surg. 2005; 241: 529-533.

3. Hughes J.A., Hatrick A. and Rankin S. Computed tomography findings in an inflamed Meckel diverticulum. Brit. J. Radiol. 71: 882-883.

4. Moore T. and Johnston A.O. Complications of Meckel's diverticuluin. Brit. J. Surg. 1976; 63: 453-454.

5. Cullen J.J., Kelly K.A. and Moir C.R. Surgical management of Meckel's diverticulum. An epidemiologic, population-based study. Ann. Surg. 1994; 220: 564-568.

6. Kamdar H.H. and Knight E.O. Meckel's diverticulum. East Afr. Med. J. 1973; 50: 426-431.

7. Levy A.D. and Hobbs C.M. From the archives of the AFIP. Meckel diverticulum: Radiologic features with pathologic correlation. Radiographics. 2004; 24: 565-587.

8. Bemelman W.A., Hugenholtz E. and Heij H.A. Meckels diverticulum in Amsterdam: Experience in 136 patients. World J. Surg. 1995; 19: 734-736.

9. Stone P.A., Hofeldt M.J., Campbell J.E., Vedula G., Deluca J.A. and Flaherty S.K. Meckel diverticulum: Ten-year experience in adults. South Med. J. 2004; 97: 1038-1041.

10. Bennet G.L., Bimbaum B.A. and Baithazar E.J. CT of Meckel diverticulitis in 11 patients. AJR. 2004; 182: 625-629.

11. Grinsell D. and Donaldson B. Giant Meckel's diverticulum with enterolith formation. ANZ. J. Surg. 2003; 73: 968-969.

12. Ludtke F.E., Mende V., Kohier H. and Lepsien G. Incidence and frequency or complications and management of Meckel's diverticulum. Surg. Gynecol. Obstet. 1989; 169: 537-542. 
13. Leijonrnarck C.E., Bonman-Sandelin K., Frisell J. and Raf L. Meckel's diverticulum in the adult. Brit. J. Surg. 1986; 73: 146-149d.

14. Mackey W.C. and Dineen P. A fifty-year experience with Meckel's diverticulum. Surg. Gynecol. Obstet. 1983; 156: 56-64.
15. Soltero M.J. and Bill A.H. The natural history of Meckel's diverticulum and its relation to incidental removal: a study of 202 cases of diseased Meckel's diverticulum found in King County, Washington, over a fifteen year period. Amer. J. Surg. 1976; 132: 168-173.

\section{CONFERENCE ANNOUNCEMENT}

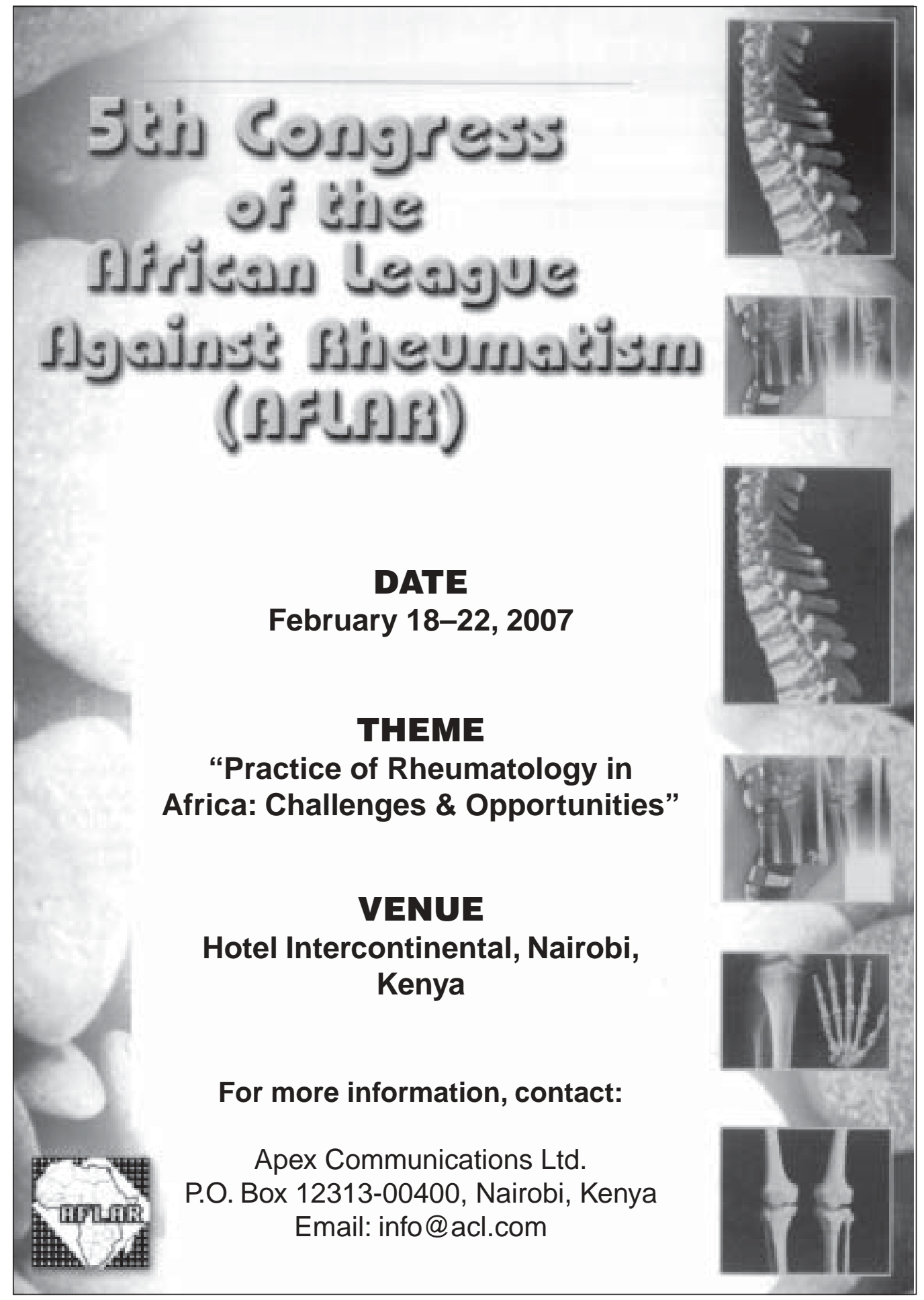

